\title{
Dublin City University - toward a sustainable campus: water
}

\author{
Samantha Fahy ${ }^{*}$ \\ Dublin City University, Glasnevin, Dublin 9, D09 W6Y4, Ireland
}

\begin{abstract}
Dublin City University, originally established in 1989, is located approximately $5 \mathrm{~km}$ to the north of Dublin City Centre and is the most significant and comprehensive provider of university education on the rapidly growing and economically important Irish Eastern corridor. DCU is committed to embedding an ethos of sustainability across the entire institution. Sustainable operations are a core element of the DCU Sustainability Plan. Baseline ecological footprint metrics have been agreed and ambitious targets are set on an annual basis to reduce these with the eventual target of delivering a carbon neutral campus. Such baselines have been agreed for all campuses for water consumption. Several projects have been undertaken both on an operational and research footing to address consumption levels. Such projects include full water surveys of all campuses leading to significant savings due to fixing of leaks. In addition to operational projects, DCU focuses on educating and information its internal and external communities raising awareness of the importance of this essential resource and seeking behavioural change to reduce consumption and increase the implementation of water efficient principles and practices.
\end{abstract}

\section{Introduction}

Dublin City University (DCU), originally established in 1989 by the University statue, is located to the north of Dublin City, Ireland and is the most significant and comprehensive provider of university education on the rapidly growing and economically important Irish Eastern corridor.

There have been some significant changes in DCU over the past couple of years. September 2016 saw the completion of the process by which St Patrick's College Drumcondra (SPD), Mater Dei Institute (MDI) and Church of Ireland College of Education (CICE) were fully incorporated with DCU. From this date, all students and staff of St Patrick's College, Mater Dei Institute and the Church of Ireland College of Education are students and staff of DCU.

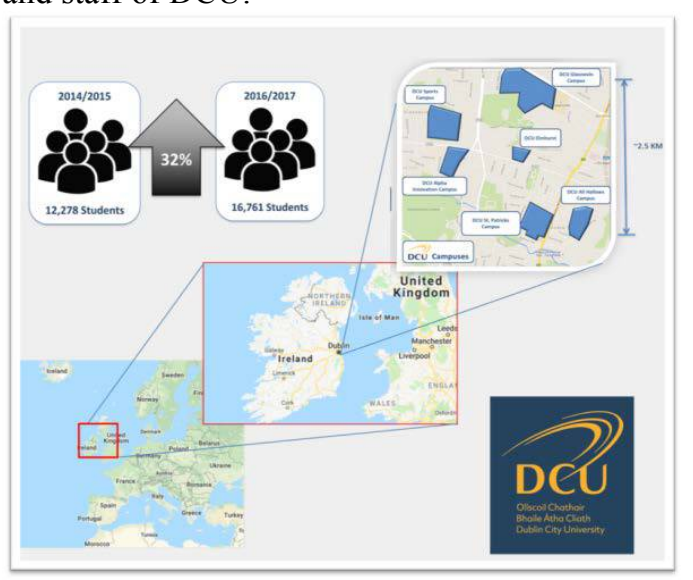

Fig. 1. DCU location 2018
This newly expanded DCU hosts over 17,000 students across five faculties Humanities \& Social Sciences, DCU Institute of Education, Science \& Health, Engineering \& Computing and DCU Business School with a continuing focus on personal, academic and professional life-skill development. Fundamental to the DCU ethos is open access to education for all. The DCU Access programme was established more than two decades ago and identifies and supports students from groups currently under-represented in higher education. In 2017, DCU supported nearly 1,300 access students, making it the largest such programme by far in any Irish university. In addition, DCU is the first Irish "University of Sanctuary", awarded by the City of Sanctuary, in recognition of a range of initiatives demonstrating commitment to welcoming asylum seekers and refugees into the university community and to fostering a culture of inclusion for all. The Age-Friendly University (AFU) initiative at DCU is committed to widening access to higher education, and this includes enhancing the lives of older members of the community through innovative educational programmes, research agenda, curriculum development, online education, health and wellness activities, arts and culture programme and civic engagement opportunities.

\section{University strategy $\mathbf{2 0 1 7 - 2 0 2 2}$}

2017 seen the launch of the new DCU Strategic Plan: TALENT, DISCOVERY, AND TRANSFORMATION (2017 - 2022) [1]. In presenting this plan the DCU President Prof. Brian MacCraith said

\footnotetext{
${ }^{*}$ Corresponding author: samantha.fahy@dcu.ie
} 
"Our purpose must surely be to address the major challenges facing the world today and to develop the talent and knowledge that society needs."

Continuing its mission statement DCU aims to transform lives and societies through education, research, innovation and engagement.

DCUs vision is to be a globally significant University of Transformation and Enterprise that is renowned for among other things its commitment to sustainability. This is clearly articulated in one of the nine strategic goals for the University over the next five years Strategic Goal 8: Place sustainability at the core of the university.

At the core of the Strategic Plan 2017 -2022, DCU will seek to further develop and implementation the DCU Sustainability Plan created by a cross-institutional Sustainability Council. This council will also play a key role in monitoring the implementation of the plan.

Sustainability will play a key role in academic and research activities, with a view to enhancing the insight and commitment of students, the principles of sustainability and sustainability literacy will be integrated into all the undergraduate curricula. Specific degree programme(s) will be developed at postgraduate level. Research focusing on sustainability will continue to be focused on and fostered.

\section{Management and operations}

There is strong evidence that Higher Education Institutions (HEIs) are in a prime position to demonstrate strong leadership to promote and support the embedding of sustainable practices not just within their own institution but as a broader example to the industry and society [2-4]. University graduates can be empowered with an understanding of sustainable and the role they must play, research departments can develop the innovation solutions (technical and non-technical), campuses, working together with industry can act of living labs to test and demonstrate these and other innovative solutions, all on a campus that utilising sustainable practices in its daily operations demonstrating to society the realisable possibility of practicing what one preaches.

Water is perceived as an infinite resource; however it is easily impacted by human activity and needs to be conserved for the benefit of health and life on the planet.

According to current estimates [5] each person in Ireland consumes $\sim 150$ litres of water per day $(54,750$ litres of water per person each year) most of which is flushed away every day. Annual consumption rate on the DCU campuses are between $180 \mathrm{k} \mathrm{m} 3$ - 220k m3 per annum. Major stakeholder have been identified and for the past number of years DCU has commissioned expert reports on water consumption on the DCU Campuses. Large number of major and minor leaks were identified and fixed leading to significant $(+30 \%)$ consumption reductions.
In November 2017 DCU was awarded the ISO50001 management standard for both Energy and water management on campus. This award was achieved not only through the reduction in leaks but also in the implementation of several infrastructural measures over the past 3-5 years including waterless urinals, reduced flow water taps and shower heads along with several measures to engage the university community and increase awareness of consumption habits and how to reduce these.

\section{Green campus at DCU}

Engaging the internal and external communities at DCU has been a focus of Sustainability strategy for some time. In 2012 DCU signed up to the An Taisce Green Campus programme which "encourages practical environmental education and the empowerment of campuses to become exemplar in environmental stewardship" and which has been in operation in Ireland since 2007 [6]. This programme raises the profile of sustainability actions across campus and creates the platform to extend and translate the learning from Glasnevin Campus to the new incorporated campuses. In early 2018 following a rigorous assessment DCU St. Patricks Campus was also awarded Green Campus Status.

A primary focus of the Green Campus programme is educating and informing all members of the DCU Community, all staff (academic, research, administrative and technical), all students (undergraduate and postgraduate) along with societal groups and enterprise partners who are linked to DCU. The operational projects have of course a very significant impact on the water consumption levels within the university however to translate this impact to a global scale behavioural change is needed across the board.

The Green Campus programme at DCU had undertaken many engaging and compelling projects working with a broad range of stakeholders that have focused on developing a understanding of the limited resources available and identification of sustainable solutions.

\subsection{Water consumption in the DCU sports complex}

A student driven project was undertaken in 2015/2016 to investigate water consumption in the sports complex. This project demonstrated the importance of knowing where your water is consumed - results showed that the pool consumed $3,000-5,000 \mathrm{M}^{3}$ per annum while in comparison the shower facilities were a factor of greater at $\sim 46,000 \mathrm{M}^{3}$ per annum.

\subsection{Rain water harvesting at DCU}

Over the years there have been several projects undertaken on RWH at DCU including the installation of a RWH system on the 1.6-acre DCU Community Garden. Total volume of capture water is $\sim 3,000$ liters however this proved not to be sufficient for summer 
conditions and in addition a 5-6k liters holding pond was also installed in the garden to ensure sufficient water in the growing season. In addition to providing a reserve of water this pond has also enhanced the biodiversity within the garden attracting frogs, newt and other water dependant plants and animals into the garden.

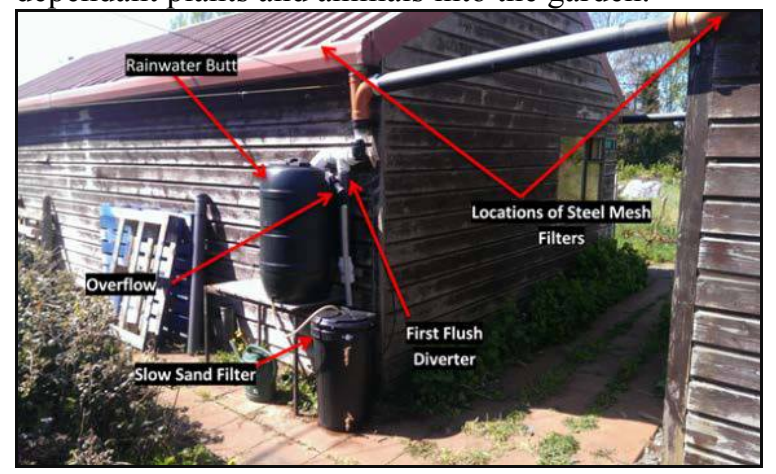

Fig. 2. Installed RWH system and filtration system at DCU community garden

Supporting the RWH system in the community garden a student undertook their final year project on the designed a relatively cheap and robust sand filtration system that removed a large portion of contaminant in the water so that it was in essence potable. The model for this filtration system was disseminated to other community gardens in the greater Dublin area.

A feasibility study was undertaken to assess the potential for RWH as a recourse on the Glasnevin Campus indicating that there was significant potential for the reuse of water on campus however prohibitive regulation has limited the ability to implement this solution

\subsection{Promoting water awareness}

On an annual basis the DCU Green Committee hosts either green weeks or green days to promote awareness of sustainability issues. This includes a regular intergeneration water rocket-launching competition where primary (6-12yrs), secondary (12-18yrs) and university (18-99yrs) students design, create and launch their own rockets using recycled plastics bottles and harvested water from the DCU Garden.

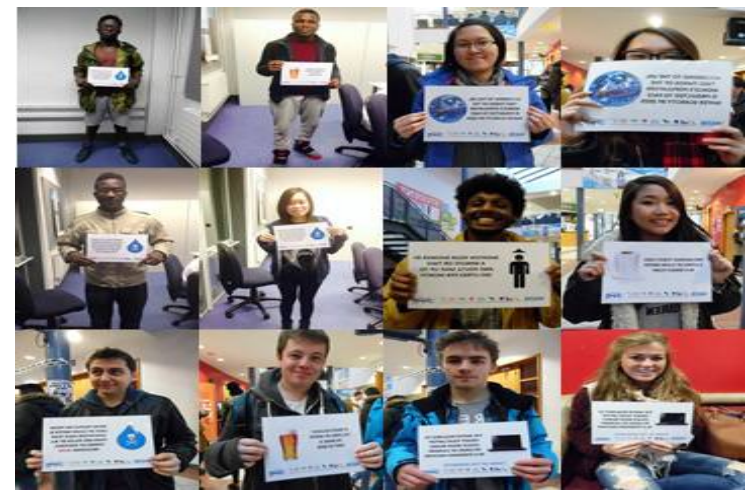

Fig. 3. Participants in world water day at Dublin City University Glasnevin Campus.
Also on world water day DCU media students run awareness campaigns using social media such as facebook/snapchat/ instagram. Many are surprised on what they have discovered like how much of water you have to use to flush a toilet and how much water you can save when you shorten your shower time.

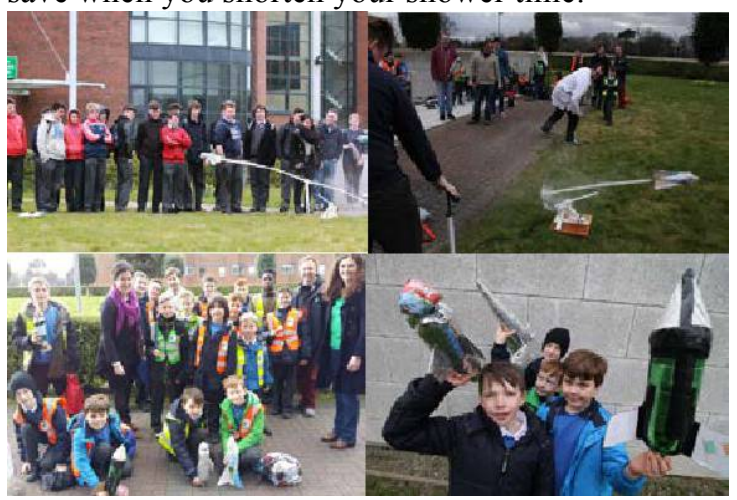

Fig. 4. Water awareness campaign with Students on social media

\subsection{Hot water in public sanitary facilities}

DCU, along with nine other partner Universities, are participating in the Global Consortium for Sustainability Outcomes (GCSO) project on trialling the removal of hot water from public sanitary facilities. DCU plan to remove hot water from the majority of sanitary facilities in one designated building for the period of one year and closely monitor the impact and perspectives of staff, students and other building users. Hot water is not required for hygiene purposed and due to legionnaire's disease, all public hot water system must hold hot water at circa $60 \operatorname{deg} C$ to prevent spread of the disease. The provision of hot and cold water is however required under national building and health \& safety regulations. Significant water and energy saving and associated greenhouse gas emissions reduction for the building have been estimated over the period. Working closely with Dublin City Council and the Health and Safety Authority this project aims to provide the necessary data to amend legislation and regulation for all future buildings in Ireland.

\subsection{Water education and research at DCU}

The DCU Water Institute is developing and applying innovative approaches to the specific challenges of water quality, delivery and management. The DCU Water Institute will be a state of the art research facility, situated on the DCU campus, and focused on solving national and global water-related problems through excellence in research, education and innovation. Through the work of its 30 Principal Investigators, the Water Institute aims to achieve safe, secure drinking water, healthy aquatic ecosystems and reliable, energy efficient, quality water supplies for a sustainable economy. 


\subsection{Community engagement and social enterprises}

DCU does not reside in an ivory tower, it is very much engaged with it local communities and enterprises and support many initiatives to promote awareness and understanding of sustainability and the sustainable development goals.

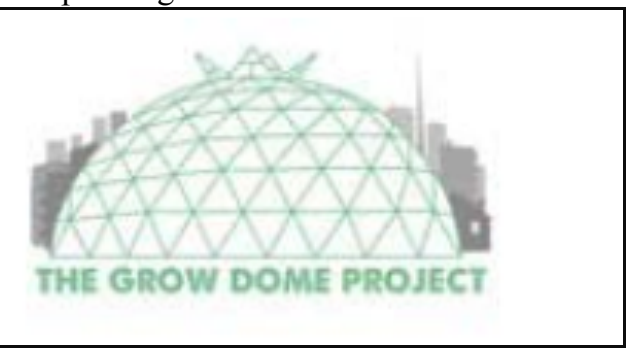

Fig. 5. Geodesic dome using aquaponics

One such initiative is a partnership with a local social enterprise that has been established in the DCU Community Garden. The Grow Dome Project uses harvested rain water to grow salads and herb for commercial use.

\section{Conclusions}

Water, in particular potable water, is one of the greatest challenges facing global societies today. Academic Institutions are ideally positioned to educate and communicate the significance of the challenge faced and to implement and demonstrate the measures necessary to protect this essential natural resource. DCU has taken a holistic approach to this challenge, using its campuses as living labs to demonstrate new technologies, empowering and enabling staff and students to engage in the process. Operational excellence is key to developing and implementing solutions. DCU has demonstrated significant savings in water usage over the past number of year through developing and deploying best practice in the identification and elimination of leaks within the DCU water network. Furthermore
DCU has tested and implemented several waters saving technologies to reduce water consumption. However, without the engagement and contribution of the members of the DCU community, including all staff, students, researchers and visitors the impact of technological solutions will be limited.

DCU has focused significant efforts at educating and informing its community through compelling interactive initiatives. Embedding behavioural change is fundamental to scaling sustainable solutions to the broader community.

DCU seeks to demonstration leadership in addressing the grand challenge of our time by placing sustainability at the core of the institution as an exemplar for industry and society. Using the campuses as living laboratories, DCU is supporting and enabling the conception, development and implementation of viable solutions.

\section{References}

1. Dublin City University, Available online at http://www.dcu.ie/sites/default/files/ marketing/ digitalmedia/presidents-office/strategic-plan/ index.html

2. W. E. Kirwan, Innovative Higher Education, 35, 101-111, (2010)

3. M. Ralph, W. Stubbs, Higher Education, 67, 71- 90. (2014)

4. L. Sharp, International Journal of Sustainability in Higher Education, 3(2), 128-145 (2002)

5. The independent survey was carried out by Ignite Research among 2011 people aged 16+ in ROI

6. Green-Campus, An Taisce Environmental Education Unit, Available online at http://www.greencampusireland.org/about/ 